\title{
Evaluation of cardiovascular risk according to framingham tables in a colombian population
}

\begin{abstract}
Introduction and objective: Cardiovascular disease is the leading cause of death worldwide, but is caused by a variety of risk factors leading to elevate mortality rates. The objective of this research was to determine the cardiovascular risk according to Framingham test in patients attending physiotherapy.

Methods and materials: An study observational and descriptive in which 462 patients were included; after the exclusion process was a sample of 338 subjects (256 women and 82 men) with a mean age of $47 \pm 11$ years. The Framingham test was used to estimate the risk of cardiovascular disease in patients attending physiotherapy. Anthropometric measurements, vital signs and a questionnaire to identify cardiovascular risk factors.

Results: After the intervention, we observed that when applying the test of Framingham $76 \%$ had low risk, $13.6 \%$ medium risk and high risk $10.3 \%$; Moreover $63.3 \%$ were overweight /obese, being higher in overweight men $(27.02 \pm 1.39$ vs $26.75 \pm 2.23$, $\mathrm{p}=0.337)$ and obesity for women $(32.72 \pm 8.38$ vs $31.35 \pm 4.24, \mathrm{p}=0.094)$.

Conclusion: In applying the test showed a low Framingham risk in most patients who attend physiotherapy and those women have a higher prevalence of family history for cardiovascular disease, hypertension, intake of fatty foods and obesity. Men are more likely to be overweight, smoking and alcohol intake; for diabetes were no significant differences.
\end{abstract}

Keywords: cardiovascular, cardiovascular disease, framingham, risk factors, overweight, obesity

\section{Introduction}

Hypertension is a cardiovascular risk factor very prevalent in the world, which is especially overwhelming in low and middle income countries. ${ }^{1}$ Every year more people die from cardiovascular disease (CVD) over any other cause. It is estimated that 17.5 million people died in 2012, representing $31 \%$ of all deaths worldwide. Of these deaths, 7.4 million were due to coronary heart disease, and 6.7 million due to cardiovascular accidents (CVA). ${ }^{2}$ In Colombia there are the leading cause of death, in both sex over 45 years, surpassing even the violent deaths and deaths associated with all cancers combined. Likewise, ischemic heart disease and cerebrovascular disease are the two causes that produce the highest rates of disability and mortality in that country. ${ }^{3}$ Moreover, it is widely accepted that age, gender, high blood pressure, smoking, dyslipidemia, sedentary lifestyle and diabetes are the greatest risks factors for CVD among many more as shown in the book of Cardiovascular Risk Factors - Examination, evaluation, diagnosis and most relevant aspects of the risk factors; It is also recognized that risk factors for CVD group and interact multiplicatively to promote vascular risk. ${ }^{4}$

Nowadays, multiple tools for estimating cardiovascular risk are available $^{1}$, most of them have been derived from the Framingham study, ${ }^{5}$ this allows one a healthy person to estimate the risk of suffering from ischemic heart disease in the next ten years, using the data of age, sex, body mass index, systolic blood pressure (BP) and presence or absence of diabetes and smoking. ${ }^{6}$ In Cúcuta, cardiovascular diseases are a priority in terms of public health. ${ }^{7}$ Therefore, the objective of this study was to demonstrate the cardiovascular risk according to the Framingham test in patients attending cardiopulmonary physiotherapy in the city of Cúcuta, Colombia. According to this, it is very important to know the cardiovascular risk factors (CRF) most prevalent in the
Volume 12 Issue I - 2019

\author{
Pereira Rodríguez Javier Eliecer,' Boada \\ Morales Lorena, ${ }^{2}$ Peñaranda Florez Devi \\ Geesel,', Guerrero-Sanchez Johanna,' \\ Rodríguez Luján Griselda,' Santamaría Perez \\ Karla Noelly,' Duran Sanchez Rogelio' \\ 'Physiotherapist, Cardiopulmonary Rehabilitation Specialist, \\ Instituto Profesional en Terapias y Humanidades, México \\ ${ }^{2}$ Physiotherapist, Prescription Specialist of the exercise, México \\ ${ }^{3}$ Specialist in Neurorehabilitation, Instituto Profesional en \\ Terapias y Humanidades, México
}

\begin{abstract}
Correspondence: Javier E Pereira Rodriguez, Physiotherapist, Cardiopulmonary Rehabilitation Specialist, Master of Science in Health, Master of Educational Innovation, Momentum research group, Instituto Profesional en Terapias y Humanidades, México, Email Jepr87@hotmail.com
\end{abstract}

Received: October 25, 2018 | Published: January 03, 2019 population that attends cardiopulmonary physiotherapy; due to the multiple non-communicable chronic diseases associated with CRF. Besides, to evaluate the individual risk implementing preventive strategies that include a complete and direct treatment to their alterations. That is why, the physiotherapist must focus their strategies to:

a. Guided interventions towards changing lifestyle and acquiring healthy habits. Also, promote the different lifestyles that have broadly revealed to be effective in cardiovascular prevention: Exercise, healthy diet, non-smoking, no- alcoholic beverages in excess, weight control and and adequate abdominal perimeter.

b. Interdisciplinary work for pharmacological measures in the indicated cases, always depending on the risk factor as well as the overall cardiovascular risk.

Therefore, the physiotherapeutic techniques of cardiovascular prevention to reduce the risk, are achieved through the stratification of cardiovascular risk. Then, it is necessary to modify behaviors and healthy lifestyles, using the most effective therapeutic strategy. It is important to mention that our cardiopulmonary patients must intervene not only for the reason of consultation, but it is also integral with an approach aimed at mitigating future multisystemic complications.

\section{Most common cardiovascular risk factors}

\section{Diabetes}

It is the major risk factor for coronary heart disease and stroke. ${ }^{8}$ Different prospective studies have shown that diabetes has the double risk in the incidence of coronary heart disease and stroke, increasing mortality from these diseases by 2 to 4 times. Based on Haffner et 
al. ${ }^{9}$ it is mentioned that the risk of CVD in patients with diabetes type 2 is similar to patients with previous myocardial infarction. The ARIC study, with a follow-up of 13.790 subjects confirmed the high cardiovascular risk of subjects with type 2 diabetes. ${ }^{10}$ The risk of coronary disease in diabetic subjects was higher than that of nondiabetics. And, the risk in diabetic patients with $\mathrm{CD}$ was higher to that in non-diabetic subjects. Also the risk was similar on diabetic patient and non-diabetic patient with coronary risk. Recently, it has been observed that high glycosylated hemoglobin levels, even in $\mathrm{f}$ values currently considered normal, increase cardiovascular risk. ${ }^{11,12}$ According to international guidelines diabetes is considered the presence of a fasting blood glucose $>7.0 \mathrm{mmol} / 1(126 \mathrm{mg} / \mathrm{dl})$ or a postprandial glycemia $>11.0 \mathrm{mmol} / 1(198 \mathrm{mg} / \mathrm{dl})$.

\section{Arterial hypertension}

In 1948 it was thought that high blood pressure was necessary to push blood through the rigid arteries at older ages, and that its existence was a normal element in aging, so it was considered appropriate to ignore high elevations or systolic blood pressure. ${ }^{13}$ Rarely, isolated systolic hypertension was seriously considered. In turn, the Framingham study and other epidemiological studies showed that systolic and diastolic blood pressure have a continuous, independent, gradual and positive association with the parameters of cardiovascular evolution. ${ }^{15,16}$ Even normal-high blood pressure values are associated with an increased risk of CD. It is also necessary to mention that this is the main challenge we have faced in recent years due to the high risk involved in terms of cardiovascular morbidity and mortality. ${ }^{18}$

\section{Overweight/obesity}

The American Heart Association (AHA) mentioned that obesity is a risk factor for cardiovascular disease. ${ }^{19}$ The risk is accentuated when obesity is predominantly abdominal. ${ }^{20}$ Obesity is an independent factor in the risk of mortality because is multifactorial. ${ }^{21,22}$ This relationship was identified by the Framingham researchers 40 years ago. ${ }^{23}$ Besides the alterations in the metabolic system, when an excess of adipose tissue accumulates, various adaptations of the cardiac structure and functions are produced. ${ }^{24}$ Occidental studies have shown a relationship between obesity and cardiovascular mortality. Therefore, it is very important to consider the presence of a BMI $\geq 30 \mathrm{~kg} / \mathrm{m}^{2}$ or an abdominal perimeter at waist level $\geq 102 \mathrm{~cm}$ in men and $\geq 88 \mathrm{~cm}$ women as a cardiovascular risk factor. ${ }^{25}$ Currently, prevention, control of overweight and obesity in adults and children has become a key element for the prevention of cardiovascular diseases. ${ }^{15}$

\section{Smoking}

The risk associated with smoking depends on the amount smoked and the duration of the habit. In the INTERHEART study, the OR associated with smoking was 2.93 and it reached 9.16 in those who smoked more than 40 cigarettes a day, but even those who smoked between 1 and 5 cigarettes a day had an increased risk of 38\%. In addition, it is directly responsible for $37 \%$ of the risk attributable to Acute Myocardial Infarction (AMI) in the INTERHEART study worldwide. ${ }^{27}$ In the study by Moreno-Esteban et al. ${ }^{28}$ it is mentioned that patients who continued smoking after an AMI had a greater risk of suffering a cardiovascular event than those who abandoned this habit $(70.8 \%$ vs. $17.5 \%)$. For this reason, tobacco consumption is the main preventable cause of morbidity and mortality in the world, it is an important risk factor for coronary and cerebrovascular disease, among other significant morbid conditions. Therefore, the non-smoking should be crucial because it generates important health benefits and remembering that the risk affects not only the smoker but also those exposed passively. ${ }^{29}$

\section{Dyslipidemia}

Elevated LDL (Low Density Lipoprotein) cholesterol is the main cause of coronary heart disease (CAD) ${ }^{30}$ Researchers from the Framingham study have reported that elevated triglyceride levels are an independent risk factor. ${ }^{31}$ Dyslipidemia plays an important role along with insulin resistance which is acquired largely by obesity and physical inactivity, although genetic factors play a very important factor; this combination being the triggers for Metabolic Syndrome. ${ }^{32}$ Among the various factors involved in cardiovascular diseases, hypercholesterolemia, and mainly high cholesterol values linked to low density proteins (LDL-c), are considered major or causal factors ${ }^{33,34}$ and strategies aimed at achieving their control are the most effective. The Multiple Risk Factor Intervention Trial (MRFIT) showed a continuous and gradual relationship between cholesterolemia and total mortality due to ischemic heart disease. ${ }^{35}$ Moreover, reducing cholesterolemia decreases the incidence and mortality due to ischemic heart disease and cardiovascular disease in general, both in primary and secondary prevention. ${ }^{36}$

\section{Physical inactivity}

Several epidemiological studies have shown that there is a relationship between physical inactivity and $\mathrm{CD} \cdot{ }^{37}$ The relative risk of death from $\mathrm{CD}$ in a sedentary individual compared to an active individual is 1.9 (95\% confidence interval [CI], 1.6-2.2) ${ }^{15}$ The WHO reported that the sedentary lifestyle is among the 10 most important causes of death and disability worldwide. Sedentary lifestyle can elevate lipid levels to the range of risk for Metabolic Syndrome and can act by altering the cardiovascular reserve mediated by coronary blood flow. Nevertheless, healthy levels of physical activity in childhood can prevent obesity in childhood and later in adult life. ${ }^{38}$

\section{Alcohol intake}

Alcohol is a drug of legal consumption related to multiple diseases that is on the third place of risk factor representing of DALYS, only behind tobacco and high blood pressure. ${ }^{39}$ The relationship of alcohol consumption with $\mathrm{CD}$ is currently under discussion, although there is evidence that small amounts, less than $25 \mathrm{~g} /$ day, could be a factor that reduces the risk of ischemic heart disease, ischemic stroke and diabetes type $2^{39,40}$ Therefore, the effects of alcohol on health depend on the amount ingested and the patterns of consumption, the presentation of curve J, which shows the effects of alcohol on health. In this curve, it has been described that low alcohol consumption is associated with a reduction in the general mortality of $18 \%$ and cardiovascular disease of $30 \%{ }^{42}$ On the other hand, excessive consumption may confer risk of $\mathrm{CD}^{43-45}$ has been directly associated with smoking ${ }^{46}$ and is associated with a higher rate of general mortality. ${ }^{38}$

\section{Family background}

The importance of hereditary factors is poorly understood. It is believed that inheritance may be important in blood pressure, glucose tolerance, increase in uric acid and plasma triglycerides, while in the families, environmental factors are related to lipoproteins, total cholesterol and the hematocrit. Studies have been carried out in which a direct relationship was observed between the family history of risk 
and cardiovascular disease. ${ }^{47,48}$ A study by Marenberg et al. showed that in youth, death from CVD is influenced by genetic factors; however, the genetic effects decrease in advanced ages in which environmental factors can play a more important role. ${ }^{49,50}$

\section{Materials and methods}

An observational and descriptive study was carried out to quantify the cardiovascular risk, with a sample of 462 patients of which, after the exclusion process, there was a sample of 338 subjects $(256$ women and $82 \mathrm{men}$ ), with an average age of $47 \pm 11$ years, who attended cardiopulmonary physiotherapy, with different diagnoses such as hypertension, diabetes, asthma, COPE, cystic fibrosis, chronic bronchitis and sedentaris. These patients had to meet the inclusion criteria; which were: No personal history of acute myocardial infarction or heart disease. They had to sign an informed consent, which was reviewed and approved by the ethics committee of the IPS Rehabilitar Cúcuta and its respective research group Rehabilitar $\mathrm{CI}$ and finally, it should guarantee the information provided to the researchers. On the other hand, we excluded patients who did not meet the age range established to apply the Framingham test (30 years to 74 years), did not have inclusion criteria for the calculation of cardiovascular risk, did not sign informed consent, provided wrong information or do not wish to participate in the present investigation.

For the collection of sociodemographic, anthropometric and physiological data an instrument was used, which was completed by questioning the patient. The sociodemographic measurements (gender, age, ethnicity, identification of risk factors, personal history, family history), physiological (heart rate, and blood pressure) and anthropometric measurements (weight, height, BMI) were carried out using the balance (Health or Meter) previously calibrated (precision $=0.1 \mathrm{~g}$ and $0.1 \mathrm{~cm}$ respectively), the weight and height of the evaluated patients were determined, placing the patient standing, with the head in Frankfort plane and with the shoulders relaxed. The $\mathrm{Z}$ score (Z-score) was obtained for the BMI $\left(\mathrm{kg} / \mathrm{m}^{2}\right)$ through Excel, developed based on the WHO reference. The study population was categorized as underweight, normal weight, overweight and obesity.

The Framingham test protocol was performed according to the Framingham Heart Study "A Project of the National Heart, Lung and Blood Institute and Boston University with the Calculator prepared by R.B. D'Agostino and M.J. Pencina based on the publication of D'Agostino et al. in Circulation, ${ }^{51,52}$ where cardiovascular risk was calculated and the analysis was made considering three risk categories: low $(<10 \%)$, medium $(10 \%$ to $19 \%)$ and high $(20 \%))^{53}$ It should be noted that the Framingham test is a cardiovascular risk measurer for use in primary care, which predicts the risk at 10 years, in individuals 30 to 74 years of age, without CVD at baseline, using age as predictors, diabetes, smoking, systolic blood pressure with treatment or without treatment, body mass index (BMI). ${ }^{52}$

\section{Statistic analysis}

All the information collected was typed and analyzed through Excel and STATA 12 statistic program, We applied descriptive statistics, composed of average and standard deviation. And then compare between them using the Mann-Whitney U Test.

\section{Results}

Of the 462 initial patients,were excluded 124 because they did not have the age allowed for inclusion in the Framingham test, therefore, the total sample was 338 patients with an average age for both genders of $47 \pm 11$ years. $75.73 \%(n=256)$ of the sample consisted of women and $24.26 \%(\mathrm{n}=82)$ were men. The prevalence of cardiovascular risk factors from highest to lowest risk were: Family history $(62.13 \%)$, food intake with high fat levels $(30.17 \%)$, hypertension $(26.03 \%)$, intake of alcohol (10.35\%), smoking (8.87\%) and finally diabetes mellitus $(8.57 \%)$. Most of them started together in the same patient (Table 1). Likewise, a higher percentage of men compared to women was determined for risk factors of smoking (18.29\% vs. 5.85\%) and alcohol intake $(24.39 \%$ vs. $5.85 \%)$; and on the other hand, women were more prevalent in arterial hypertension $(26.95 \%$ vs $23.17 \%)$, ingestion of fatty foods (30.85\% vs $28.04 \%)$ and family history $(66.79 \%$ vs. $47.56 \%)$.

Table I Characterize of the population

\begin{tabular}{|c|c|c|c|c|}
\hline Variable & Quantity & Feminine & Masculine & Average \\
\hline Muestra total & & & & 338 \\
\hline Age & & & & $47 \pm 11$ años \\
\hline Kind & 338 & 256 & 82 & 100 \\
\hline \multicolumn{5}{|l|}{ Ethnic } \\
\hline White & 105 & 88 & 17 & 31,06 \\
\hline Mestizo & 226 & 164 & 62 & 66,86 \\
\hline Afrocolombiano & 7 & 4 & 3 & 2,07 \\
\hline \multicolumn{5}{|l|}{ Risk factors } \\
\hline Smoking & 30 & 15 & 15 & 8,87 \\
\hline Alcohol intake & 35 & 15 & 20 & 10,35 \\
\hline $\begin{array}{l}\text { Hypertensión } \\
\text { arterial }\end{array}$ & 88 & 69 & 19 & 26,03 \\
\hline Diabetes Mellitus & 29 & 22 & 7 & 8,57 \\
\hline $\begin{array}{l}\text { intake of fatty } \\
\text { foods }\end{array}$ & 102 & 79 & 23 & 30,17 \\
\hline History family & 210 & 171 & 39 & 62,13 \\
\hline \multicolumn{5}{|l|}{$\begin{array}{l}\text { Anthropologist } \\
\text { - IMC }\end{array}$} \\
\hline Infrapeso & 4 & 1 & 3 & 1,18 \\
\hline Normopeso & 120 & 91 & 29 & 35,50 \\
\hline Overweight & 123 & 87 & 36 & 36,39 \\
\hline Obesity & 91 & 77 & 14 & 26,92 \\
\hline \multicolumn{5}{|l|}{$\begin{array}{l}\text { Tensión arterial - } \\
\text { Sistole }\end{array}$} \\
\hline$<120 \mathrm{mmhg}$ & 239 & 185 & 54 & 70,71 \\
\hline $120-139 \mathrm{mmhg}$ & 62 & 45 & 17 & 18,34 \\
\hline $140-159 \mathrm{mmhg}$ & 32 & 23 & 9 & 9,46 \\
\hline$>160 \mathrm{mmhg}$ & 5 & 3 & 2 & 1,47 \\
\hline
\end{tabular}

The Table 2 shows the distribution of the studied population by cardiovascular risk category for each gender, with its respective risk prediction for cardiovascular disease at 10 years according to the Framingham test, the present investigation was able to determine that $76 \%$ of the population studied presented low risk, $13.6 \%$ medium risk and $10.3 \%$ high risk. Additionally, when we calculated the body mass index (BMI), by means of the weight on the squared height, it was 
determined that $1.18 \%$ of the total population presented underweight, $35.5 \%$ normal weight, $36,39 \%$ and $26.92 \%$ for overweight and obesity respectively. Thus, the women with the highest prevalence of obesity (32.72 \pm 8.38 vs $31.35 \pm 4.24, \mathrm{p}=0.094)$ and little difference in normal weight (M: $21.82 \pm 3.76$ vs. $\mathrm{H}: 21.93 \pm 2.85$, $\mathrm{p}=0.790$ ) compared to men. In zum, there were higher rates of overweight in men than in women ( $27.02 \pm 1.39$ vs. $26.75 \pm 2.23$, $\mathrm{p}=0.337)$ (Table 3$)$.

Table 2 Distribution of cardiovascular risk according test of framingham

\begin{tabular}{llllll}
\hline Riesgo & \multicolumn{2}{l}{$\begin{array}{l}\text { Feminine } \\
(\mathbf{n = 2 5 6 )}\end{array}$} & $\begin{array}{l}\text { Masculine } \\
(\mathbf{n = 8 2})\end{array}$ & Average (n=338) \\
\hline & $\mathrm{N}$ & $\%$ & $\mathrm{~N}$ & $\%$ & \\
\hline Short & 215 & 83,98 & 42 & 51,21 & 76,03 \\
Medium & 29 & 11,32 & 17 & 20,73 & 13,60 \\
High & 12 & 4,68 & 23 & 28,04 & 10,35 \\
\hline
\end{tabular}

Table 3 Comparison of anthropologist, men versus women

\begin{tabular}{llllll}
\hline IMC & $\begin{array}{l}\text { Feminine } \\
(\mathbf{n = 2 5 6 )}\end{array}$ & $\mathbf{N}$ & $\begin{array}{l}\text { Masculine } \\
(\mathbf{n = 8 2})\end{array}$ & $\begin{array}{l}\text { Average } \\
(\mathbf{n = 3 3 8})\end{array}$ \\
\hline Infrapeso & 1 & $\mathbf{\%}$ & $\mathbf{n}$ & $\mathbf{\%}$ & \\
Normopeso & 91 & 35,54 & 29 & 3,65 & 1,18 \\
Overweight & 87 & 33,98 & 36 & 35,36 & 35,50 \\
Obesity & 77 & 30,07 & 14 & 43,90 & 36,39 \\
\hline
\end{tabular}

\section{Discussion}

The risk coronary of cardiovascular the show probability of show disease coronary o cardiovascular in a period of time determined, generally five on teen years. ${ }^{54}$ However criticisms have arisen to prediction of the risk to 10 years in circumstances that the risk of a cardiovascular event is magnified in the longer term (riesgo de por vida, "lifetime risk"). ${ }^{55}$ This aggregate of risk factors of the sample under study allows us to identify that family history $(62.13 \%)$, the overweigt $(36.39 \%)$, the ingesta of food with high Fat levels (30.17\%) obesit y $(26.92 \%)$ and arterial hypertension $(26.03 \%)$, they are the most prevalent risk factors in the study population, although unlike the review by José GT et al, ${ }^{56}$ it was found that those evaluated had a previous diagnosis of obesity $(28.3 \%)$, followed by hypertension HT $(11.6 \%)$, depression $(10.1 \%)$, kidney disease $(7.2 \%)$, they are the most prevalent risk factors in the study population, although unlike the review by José GT et al, ${ }^{56}$ it was found that those evaluated had a previous diagnosis of obesity $(28.3 \%)$, followed by hypertension HT $(11.6 \%)$, depression $(10.1 \%)$, kidney disease $(7.2 \%)$, Diabetes mellitus $(2.2 \%)$ and $(1.4 \%)$ IAM. In the previous study, risk factors such as depression, kidney disease and acute myocardial infarction were included, which in our study were not evident but are prevalent in cardiovascular diseases, which also influence the evolution of said disease, as indicate different epidemiological studies. ${ }^{57-59}$

Similarly, to determine which population by gender had the risk factor of overweight/obesity was calculated the body mass index (IMC), and it was determined that $43.9 \%$ of men were overweight versus $33.9 \%$ corresponding to women; and for obesity, women with $30 \%$ versus $17 \%$ of men, with a total of the sample with overweigh/ obesity of $63.3 \%$. Likewise, as occurred in a study conducted in the departments of Caldas, Risaralda and Quindío where $42.9 \%$ had a BMI above normal, $31.2 \%$ with overweight and $11.7 \%$ with obesity, while $36,9 \%$ had abdominal obesity ( $55.4 \%$ women and $20.3 \%$ men). Thus, it is higher in women than in men, ${ }^{60}$ as in the present investigation.

Therefore, the absolute risk of a patient with obesity should be taken into consideration from two components: the relative risk of morbidity and mortality associated with excess weight and fat distribution by itself and the excess risk associated with the most prevalent risk factors in the overweight/obesity. ${ }^{55}$ It is striking that the study population in the Framingham test has a relatively low prevalence of cardiovascular risk $(76.03 \%)$; however, there were results with high cardiovascular risk $(10.35 \%)$. It is notable for the percentages of risk factors found in the study, that there are triggers for CVD but that they have not yet been seriously presented in each patient who has more than two risk factors. Having said that, the population with the highest cardiovascular risk (28\%) is men and in a smaller amount $(4.68 \%)$ women; This is consistent with the work carried out by Jose GT and Col. in Pereira with university employees, ${ }^{56}$ where the calculated risk levels of presenting CVD at 10 years indicate that $53.5 \%$ of the men evaluated have medium risk, on $28.6 \%$ low risk, while only $4.8 \%$ have high risk and in women $74 \%$ have low risk, while $18.7 \%$ risk medium and not finding high risk. There are similar data to conclude a higher incidence of men compared to women for the risk of CVD in the next 10 years; like the study by Edgardo et al, ${ }^{6}$ where there was a low percentage $(2.8 \%)$ of high risk women compared to men.

\section{Conclusion}

When applying the Framingham test on the population, it was evidenced low risk in both women and men and it is estimated that the cardiovascular risk is compared with many aspects that are not taken as a basis of the Framingham test, but that surround cardiovascular disease; that is, the cardiovascular risk factors identified in the study as: Family history and intake of fatty foods are the greatest predictors of cardiovascular disease, just as taking the body mass index shows that women have a higher prevalence of obesity than men. Likewise, when comparing the prevalence of each one of the cardiovascular risk factors, we can conclude that the most prevalent cardiovascular risk factors in women are the family history, the intake of fatty foods, obesity and arterial hypertension. For men it was alcoholism and overweight and in diabetes there were no significant differences by gender. On the other hand, the items registered in the Framingham test, make it necessary to create own tables according to the characteristics of our Colombian population, since there may be cultural variation that in some important way modifies the risk. It would be important and of great help a transcultural validation of the Framingham scales or the PROCAM model to determine therapeutic interventions according to the needs and cardiovascular risk. At present, a large percentage of patients who attend physiotherapy are at low risk; therefore, it is the ideal opportunity to establish healthy lifestyle habits and prevent these FRC from increasing and affecting the basic pathology of our patient of the Colombian population.

\section{Acknowledgments}

Especially the group of professionals of Rehabilitar IPS.

\section{Conflicts of interest}

The author's declare haven't none conflicts of interest. 


\section{References}

1. Ramiro AS, Miryam A, Hugo B, et al. Guías Latinoamericanas de Hipertensión Arterial. Rev Chil Cardiol. 2010;29:117-144.

2. OMS. Organización Mundial de la Salud. 2015

3. Oscar MM, Nohora IR, Álvaro R, et al. Validación de los modelos de predicción de Framingham y PROCAM como estimadores del riesgo cardiovascular en una población colombiana. Rev Colomb Cardiol. 2014;21(4):202-212.

4. Ralph BA, Ramachandran SV, Michael JP, et al. General Cardiovascular Risk Profile for Use in Primary Care, The Framingham Heart Study. Circulation. 2008;117:743-753.

5. Antonio C, José JAS, María CRP, et al. En la población Canaria, la función de Framingham estima mejor el riesgo de mortalidad cardiovascular que la función SCORE. Gac Sanit. 2009;23(3):216-221.

6. Edgardo S, Emma S, M. Victoria M, Carlos S, Manuel B, Hugo S Predicción de eventos coronarios a nueve años mediante el score de Framingham en Uruguay. Rev Urug Cardiol. 2009;24:13-21.

7. Garcia Ana, Pereira Javier. Tolerancia al ejercicio en pacientes posquirúrgicos cardiovasculares luego de la intervención con un programa de rehabilitación cardiaca fase II. Rev Colomb Cardiol. 2014;21(6):409-413.

8. Sociedada Española de Cardiologia. Guía de práctica clínica de la ESC sobre diabetes, prediabetes y enfermedad cardiovascular, en colaboración con la European Association for the Study of Diabetes. Rev Esp Cardiol. 2014;67(2):136e1-e156.

9. Sociedada Española de Cardiologia. Guía ESC 2016 sobre prevención de la enfermedad cardiovascular en la práctica clínica. Rev Esp Cardiol. 2016;69(10):939e1-e987.

10. Lee CD, Folsom AR, Pankow JS, et al. Cardiovascular events in diabetic and nondiabetic adults with or without history of myocardial infarction. Circulation. 2004;109(7):855-860.

11. Khaw KT, Wareham N, Bingam S, et al. Assocation of Hemoglobin A1c with cardiovascular disease and mortality in adults. The European Prospective investigation into cancer in Norfolk. Ann Intern Med. 2004;141(6):413-420.

12. Selvin E, Marinopoulos S, Berkenblit G, et al. Meta-analysis: glycosilated hemoglobin and cardiovascular disease in diabetes mellitus. Ann Interne Med. 2004;141(6):321-331.

13. Smirk FH, Veale AM, Alstad KS. Basal and supplemental blood pressures in relationship to life expectancy and hypertension symptomatology. N Z Med J. 1959;58:711-735.

14. Koch-Weser J. The therapeutic challenge of systolic hypertension. $N$ Engl J Med. 1973;289:481-482.

15. Christopher J O’Donnell, Roberto Elosua. Factores de riesgo cardiovascular. Perspectivas derivadas del Framingham Heart Study. Rev Esp Cardiol. 2008;61(3):299-310.

16. Whelton PK, Carey RM, Aronow WS, et al. 2017 ACC/AHA/ AAPA/ABC/ACPM/AGS/APhA/ASH/ ASPC/NMA/PCNA Guideline for the Prevention, Detection, Evaluation, and Management of High Blood Pressure in Adults: Executive Summary. Hypertension. 2018;71:1269-1324.

17. Vasan RS, Larson MG, Leip EP, et al. Impact of high-normal blood pressure on the risk of cardiovascular disease. $N$ Engl J Med. 2001;345:1291-1297.

18. Sociedad Española de Hipertensión. Liga Española para la lucha ontra la hipertensión arterial (SEH-LELHA). Guia Española de Hipertensión Arterial 2005. Hipertensión. 2005;22 Supl 2:3-69.
19. Krieger DR, Landsberg L. Mechanisms in obesity-related hypertension: role of insulin and catecholamines. Am J Hypertens. 1988;1(1):84-90.

20. Sociedad Argentina de Pediatría Subcomisiones, Comités y Grupos de trabajo. Obesidad: guías para su abordaje clínico. Resumen ejecutivo. Arch Argent Pediatr. 2016;114(2):180-181.

21. Engeland A, Bjorge T, Sogaard AJ, Tverdal A. Body mass index in adolescence in relation to total mortality: 32-year followup of 227,000 Norwegian boys and girls. Am J Epidemiol. 2003;157(6):517-523.

22. Jee SH, Sull JW, Park J, et al. Bodymass index and mortality in Korean men and women. $N$ Engl J Med. 2006;355:779-787.

23. Kannel WB, LeBauer EJ, Dawber TR, et al. Relation of body weight to developement of coronary heart disease. The Framingham Study. Circulation. 1967;35:734-744.

24. Poirier P, Giles TD, Bray GA, et al. Obesity and cardiovascular disease: Pathophysiology, evaluation, and effect of Council on Nutrition, Physical Activity, and Metabolism Statement on Obesity and Heart Disease From the Obesity Committee of the Weight Loss: An update of the 1997 American Heart Association Scientific. Circulation. 2006;113(6):898-918.

25. De Backer G, Ambrosioni E, Borch-Johnsen K, et al. European guidelines on cardiovascular disease prevention in clinical practice. Third Joint Task Force of European and other societies on Cardiovascular Disease Prevention in Clinical Practice (constituted by representatives of eight societies and by invited experts). Eur J Cardiovasc Prev Rehab. 2003;10 Suppl 1:S1-S78.

26. Luque Otero M, Martell Claros N. Hipertensión arterial y síndrome metabólico. Med Clin. 2004;123:707-711.

27. Yusuf S, Hawken S, Ounpuu S, et al. Effect of potentially modifiable risk factors associated with myocardial infarction in 52 countries (the INTERHEART study): case-control study. Lancet. 2004;364:937-952.

28. Townsend N, Nichols M, Scarborough P, Rayner M. Cardiovascular disease in Europe-epidemiological update 2015. Eur Heart J. 2015;36:2696-2705.

29. Fernando Lanas Kine, Pamela Serón. Rol del tabaquismo en el riesgo cardiovascular global. Rev Med Clin. 2012;23(5):566-578.

30. Adult Treatment Panel III. Third Report of the National Cholesterol Education Program (NCEP) Expert Panel on Detection, Evaluation, and Treatment of High Blood Cholesterol in Adults: Executive Summary. NIH Publication. 2001

31. Grupo de Trabajo de la Sociedad Europea de Cardiología (ESC) y la European Atherosclerosis Society. Guía ESC/EAS 2016 sobre el tratamiento de las dislipemias. Rev Esp Cardiol. 2017;70(2):115.e1e64.

32. Jesús Martínez Réding. Estratificación de riesgo cardiovascular. Revista Mexicana de Cardiologia. 2006;76(2):176-181.

33. Piepoli MF, Hoes AW, Agewall S, et al. 2016 European Guidelines on cardiovascular disease prevention in clinical practice: The Sixth Joint Task Force of the European Society of Cardiology and Other Societies on Cardiovascular Disease Prevention in Clinical Practice (constituted by representatives of 10 societies and by invited experts) Developed with the special contribution of the European Association for Cardiovascular Prevention \& Rehabilitation (EACPR). Eur Heart J. 2016;37(29):2315-2381.

34. Grundy SM, Pasternak R, Greenland P, et al. Assessment of cardiovascular risk by use of multiple-risk-factor assessment equations. A statement for healthcare professionals from the American Heart Association and the American College of Cardiology. Circulation. 1999;100:1281-1292. 
35. Stamler J, Wentworth DN, Neaton JD. Is relationship between serum cholesterol and risk of premature death from coronary heart disease continuous and graded? Findings in 356,222 primary screenees of the Multiple Risk Factor Intervention Trial (MRFIT). JAMA. 1986;256:2823-2828.

36. Eckel RH, Jakicic JM, Ard JD, et al. 2013 AHA/ACC Guideline on Lifestyle Management to Reduce Cardiovascular Risk. Circulation. 2013;129(25 Suppl 2):S76-S99.

37. Grupo de Trabajo de la SEC para la guía ESC 2015. Comentarios a la guía ESC 2015 sobre el tratamiento de los síndromes coronarios agudos en pacientes sin elevación persistente del segmento ST. Rev Esp Cardiol. 2015;68(12):1061-1067.

38. Mónica Sánchez-Contreras, Germán A Moreno-Gómez, Marta E MarínGrisales, et al. Factores de Riesgo Cardiovascular en Poblaciones Jóvenes. Rev salud pública. 2009;11(1):110-122.

39. Anderson P, Baumberg B. Alcohol in Europe A public health perspective. Londres: Institute of Alcohol Studies; 2006.

40. Corrao G, Bagnardi V, Zambon A, et al. A meta-analisys of alcohol consumption and the risk of 15 diseases. Prev Med. 2004;38(5):613-619.

41. O'Keefe J, Bybee K, Lavie C. Alcohol and Cardiovascular Health: The Razor-Sharp Double Edged Sword. J Am Coll Cardiol. 2007;50:1009-1014.

42. Mukamal K, Chiuve S, Rimm E. Alcohol consumption and risk for coronary heart disease in men with healthy lifestyles. Arch Intern Med. 2006;166(19):2145-2150.

43. Rimm E, Klatsky A, Grobbee D, et al. Review of moderate alcohol consumption and reduced risk of coronary heart disease: is the effect due to beer, wine, or spirits. $B M J$. 1996;312(7033):731-736.

44. Beilin L, Puddey I. Alcohol and hypertension: an update. Hypertension. 2006;47(6):1035-1038.

45. Klatsky A. Alcohol and stroke: an epidemiological labyrinth. Stroke. 2005;36(9):1835-1836.

46. Cedeño Zambrano Jaime E, Vásquez Jaramillo Paula A, Roca-Lino Vanessa E. Riesgo cardiovascular relacionado con el consumo de alcohol. Dom Cien. 2016;2(4):17-27.

47. Burke GL, Savage PJ, Sprafka JM, et al. Relation of risk factor levels in young adulthood to parental history of disease; the CARDIA Study. Circulation. 1991;84(3):1176-1187.
48. Scientific Steering Committee On Behalf Of The Simon Broome Register Group. Risk of fatal coronary heart disease in familiar hypercholesterolemia. BMJ. 1991;303(6807):893-896.

49. Marenberg M, Risch N, Berkman L, et al. Genetic susceptibility to death from coronary heart disease in a study of twins. $N$ Engl J Med. 1994;330(15):1041-1046.

50. Zdravkovic S, Wienke A, Pedersen N, et al. Heritability of death from coronary heart disease: a 36-year follow-up of 20966 Swedish twins. $J$ Intern Med. 2002;252(3):247-254.

51. Calculator prepared by RB. D'Agostino and MJ. Pencina based on a publication by D'Agostino et al. in Circulation.

52. Framingham Heart Study. Boston; 2015.

53. Edgardo S, Emma S, Victoria M, et al. Predicción de eventos coronarios a nueve años mediante el score de Framingham en Uruguay. Rev Urug Cardiol. 2009;24(1):13-21.

54. Tomas R. ¿Cuál es el riesgo cardiovascular del adulto asintomático?. Rev Chil Cardiol. 2012;31(2):134-141.

55. Diana SM, Nazly Mayerly CM, Maria FC, et al. Correlación entre parámetros antropométricos y perfil de riesgo cardiovascular estimado para la población española. Clin Invest Arterioscl. 2010;22(6):241-246.

56. José GT, José WM, Patricia GE. Aplicación de la escala de Framingham en la detección de riesgo cardiovascular en empleados universitarios. Rev Salud Pública. 2011;13(4):633-643.

57. Abraham PU, Carlos Fernando CS, Miguel Mauro OA, et al. Prevalencia de hipertensión arterial, sobrepeso y obesidad en poblaciones urbanas el estado de Sinaloa. Rev Mex Cardiol. 2012;23(1):7-11.

58. Clicerio GV, Claudio Alberto DC, Mireya ZM, et al. Risk factors associated to diabetes in Mexican population and phenotype of the individuals who will convert to diabetes. Salud pública Méx. 2014;56(4):317-322.

59. Benjamín TH, Clemente V, José RAS, et al. Frecuencia y factores de riesgo asociados a sobrepeso y obesidad en universitarios de Colima, México. Rev Salud Pública. 2010;12(2):197-207.

60. Miguel AG, Rodolfo JD, José HD, et al. Factores de riesgo cardiovascular y de enfermedades crónicas en población caficultora. Rev Salud Pública. 2012;14(3):390-403. 